\title{
Anatomical basis of lymph node detection in gynecologic cancers: a review from a surgical perspective
}

\author{
Yohann Dabi ${ }^{1,2,3}$, Sofiane Bendifallah ${ }^{1,2,3}$, Kamila Kolanska ${ }^{1,2,3}$, Anne Sophie Boudy ${ }^{1,2,3}$, Denis Querleu ${ }^{4}$, \\ Cherif Akladios $^{5}$, Sonia Zilberman ${ }^{1,2,3}$, Emile Darai ${ }^{1,2,3}$, Cyril Touboul ${ }^{1,2,3}$
}

${ }^{1}$ Department of Gynecology Obstetrics and Reproductive Medicine, Hôpital Tenon, Sorbonne University, Assistance Publique des Hôpitaux de Paris, Paris, France; ${ }^{2}$ Groupe de Recherche Clinique in endometriosis (GRC-6 Sorbonne University), Centre Expert En Endometriose (C3E), Paris, France; ${ }^{3}$ UMRS938 Sorbonne University, Paris, France; ${ }^{4}$ Department of Surgical Oncology, Institut Bergonié, Bordeaux, France; ${ }^{5}$ Department of Gynecology Obstetrics and Reproductive Medicine, Strasbourg University Hospital, Strasbourg, France

Contributions: (I) Conception and design: D Querleu, C Akladios, E Darai, C Touboul; (II) Administrative support: None; (III) Provision of study materials or patients: None; (IV) Collection and assembly of data: Y Dabi, S Bendifallah, AS Boudy, S Zilberman, K Kolanska; (V) Data analysis and interpretation: Y Dabi, S Bendifallah, AS Boudy, S Zilberman, K Kolanska; (VI) Manuscript writing: All authors; (VII) Final approval of manuscript: All authors.

Correspondence to: Prof. Cyril Touboul, MD, PhD. Department of Gynecology Obstetrics and Reproductive Medicine, Hôpital Tenon, Sorbonne University, Assistance Publique des Hôpitaux de Paris, France. Email: cyril.touboul@gmail.com.

\begin{abstract}
Pelvic and para-aortic lymphadenectomy are associated with increased risk of complications and are responsible for a significant proportion of morbidity and impaired quality of life following surgical management of pelvic malignancies. Sentinel lymph node (SLN) was developed as a trade-off between systematic and no lymphadenectomy to limit morbidity while conserving good oncological staging and outcomes. In this comprehensive review, we aimed to synthetize the anatomical basis of the SLN procedure in patients with pelvic malignancies from a surgical perspective. The reliability of the SLN procedure is based on the knowledge of the dissemination pathways for each type of tumors. The most recent understanding of the uterine lymphatic anatomy defined three consistent channels: an upper paracervical pathway (UPP) with draining medial external and/or obturator lymph nodes; a lower paracervical pathway (LPP) with draining internal iliac and/or presacral lymph nodes and the infundibulo-pelvic pathway (IPP) with a course along the fallopian tube and upper broad ligament via the infundibulo-pelvic ligament to its origin. In patients with endometrial cancer, most SLNs are located on the UPP pathway: obturator and external iliac whereas $80 \%$ of the SLNs in patients with cervical cancer are located in the external iliac, interiliac and obturator area. Surgical training is a key step toward improving detection rates and exhaustiveness of SLN research while reducing overall morbidity. This is all the more important that the indications for performing complete lymphadenectomy are becoming increasingly rare.
\end{abstract}

Keywords: Sentinel lymph node (SLN); cervical cancer; endometrial cancer; vulvar cancer; lymphatic mapping

Submitted Oct 18, 2020. Accepted for publication Dec 08, 2020.

doi: $10.21037 /$ cco-20-228

View this article at: http://dx.doi.org/10.21037/cco-20-228

\section{Introduction}

All recent efforts in gynecological malignancies revolve around reducing induced morbidity whilst conservingand even improving-good oncological outcomes. The tremendous development of minimally invasive surgery has enabled surgeons to perform radical surgeries while limiting morbidity. However, pelvic and/or para-aortic lymphadenectomy still hold a significant part of induced short and long term morbidity.

The main postoperative complications are lymphoceles in up to $38 \%$ of cases and lower limb lymphedemas in $20 \%$ 
of patients, heavily impairing quality of life (1-3).

In vulvar cancer surgery, inguinofemoral lymphadenectomy is associated with a risk of wound infection or breakdown in $20 \%$ to $40 \%$ and a risk of chronic lymphedema in $30 \%$ to $70 \%$ (4-7).

For many years, pelvic and/or para-aortic lymphadenectomy have been performed despite this morbidity because determining lymph node involvement is crucial to evaluate the prognostic and adapt subsequent adjuvant therapies. In endometrial cancer, patients with lymph node involvement (stage IIIC) have their recurrence-free survival rate drops from $87 \%$ without node involvement to $71 \%$ and $36 \%$ in women with pelvic and aortic node involvement, respectively (8). In cervical cancer, lymph node invasion has been added to the latest FIGO classification and is the most important prognostic factor identified so far (9-11).

The price of the surgical morbidity is all the more hard to bear that in most cases, whichever pelvic malignancy is considered, lymph nodes will be free of metastasis $(12,13)$. Thus, most patients will undergo an unnecessary, risky, and morbid procedure with no proven impact on survival. The sentinel lymph node (SLN) biopsy was developed as an appealing solution to solve this issue. It is defined as the very first lymph node or group of nodes that drain the anatomical region or primary tumor (14-16). If the SLN is negative, the rest of the lymph nodes draining the organ could be considered negative. In 1977, the concept of SLN was proposed by Cabanas in the management of patients with penile cancer (16). In 1992, Morton et al. (17) applied sentinel node concept successfully in clinical stage I malignant melanoma. After the proof of concept by Giuliano et al. (18) in axillary dissection of breast cancer patients, it has been quickly adopted to significantly reduce its morbidity (19-21). Histologic validation of SLN in cervical and endometrial cancer have been published for years now, using several different technics, sometimes combined. In pelvic malignancies, its indications are still evolving, as clinical trials progressively demonstrated its non-inferiority to complete lymphadenectomy, while reducing morbidity. In cervical cancer patients, SLN is currently recommended in patients staged FIGO (Federation International of Gynecology and Obstetrics) IA1 with lymphovascular space invasion (LVSI) until stage IIA1 (22).

In endometrial cancer patients, it should be offered in patients at low or intermediate risk (and could be an option in high risk patients according to NCCN guidelines) $(23,24)$.

In vulvar cancer, it is recommended in patients with tumor $\mathrm{T} 1 \mathrm{~B}<4 \mathrm{~cm}$ according to the latest FIGO classification (25).

What is implied in the concept of the SLN procedure is that the lymphatic drainage of the primary site of tumor is fully understood and that no aberrant migration pathway could be responsible of false negative results damaging for the patient. In this aim, the particularity of each cancer type SLN anatomic spread has to be known. In this review, we aimed at synthetizing the anatomical basis of the SLN procedure in patients with pelvic malignancies from a surgical perspective.

\section{Lymphatic drainage of the cervix and the corpus uteri}

The lymphatic pathway of the uterus have been extensively described since the early twentieth century as a key step to understand tumors dissemination from primary site $(26,27)$. While the cervix and the endometrium are two parts of the same organ, it seems the patterns of lymphatic spread could differs depending on embryology and mainly according to the injection site within uterus.

Geppert et al. (28) described the uterine lymphatic anatomy for endometrial cancer dissemination according to three consistent channels: an upper paracervical pathway (UPP) with draining medial external and/or obturator lymph nodes; a lower paracervical pathway (LPP) with draining internal iliac and/or presacral lymph nodes and the Infundibulo-pelvic pathway (IPP) with a course along the fallopian tube and upper broad ligament via the infundibulo-pelvic ligament to its origin.

Recently, Zuo et al. (29) validated this anatomical distribution of the lympatic channels draining endometrial tumors. Furthermore, they showed the influence of the mode of injection on the pathway preferably used to find the SLN with increased detection of para-aortic SLN using fundal injection (LPP).

As for the cervical cancer, a focus has been made to the lymphatic spread through the parametrium. BenedettiPanici et al. (30) investigated the dissemination of cervical tumors through the parametrium with three main trunks: the lateral, the anterior, and the posterior. The lateral trunk runs through the lateral parametrium is the main lymphatic drainage from the uterine cervix. As also described by Girardi et al. (31) and by Bonneau et al. (32), the lateral parametrium contains many lymph nodes and lymphatic vessels that can be privileged pathway for tumor dissemination.

The posterior lymphatic trunk runs in the sacrouterine 
ligament and along the ureter, where lymph nodes and metastases rarely were observed, justifying the rare finding of isolated metastases in the presacral and aortic lymph nodes.

\section{Lymphatic drainage of the vulva}

A specificity of vulvar cancer is its dissemination pattern, almost exclusively by local invasion and lymphatic metastasis. Hematogenous metastasis are rare.

The lymphatic drainage was first studied and described on cadavers by Sappey in 1874 but it was not until the studies of Parry-Jones in 1963 (33) and of Iversen and Aas in 1983 (34) that the lymphatic pathways of the vulva was truly understood.

Lymphatic channels of the vulva and distal third of the vagina drain via the labiocrural fold, labia, and mons veneris into the superficial inguinofemoral nodes. These first-line nodes are located medial to the saphenous vein and above the cribriform fascia and are called superficial nodes (about $8-10$ in number); Lymphatic flow then proceeds from to the deep groin nodes located beneath the cribriform fascia in the femoral triangle (35-37). The Femoral triangle is bounded superiorly by the inguinal ligament, medially by the medial border of the adductor longus muscle, and laterally by the medial border of the sartorius muscle. The uppermost deep lymph node located under the inguinal (Poupart) ligament is called "the Cloquet" node and leads to the lymphatics around the external iliac vessels. The lymphatic vessels from the vulva do not cross the midline except those coming from the median structures, i.e., the clitoris, urethral meatus and Bartholin glands that have a portion of lymphatic channels that drain directly to pelvic nodes. However, to the best of our knowledge, no isolated metastases of pelvic nodes has been described without inguinal nodes metastases.

The lymphadenectomy in inguinal area being extremely morbid, the extent of the surgical gesture has progressively been modified. An anatomical description of the extent of the inguino-femoral lymphadenectomy was proposed in 2003 by Rouzier et al. (6). They showed that medial inguinal and medial femoral lymphadenectomy was associated with the same survival but with a decreased rate of complications such as lymphedema.

We conducted a comprehensive review by searching in PubMed all English-written studies from the first report in each malignancy of the use of the SLN procedure. For cervical cancer, it was the publication by Echt et al. (38) in 1999. For endometrial cancer, it was the publication by Burke et al. in 1996 (39). For vulvar cancer, it was the publication by Levenback et al. in 1994 (40).

The MeSH Terms used were "sentinel lymph node", "lymphatic drainage", "lymphatic mapping", "cervical cancer", "cervix cancer" "cervix neoplasm", "cervical neoplasm", "endometrial cancer", "endometrial neoplasm", "vulvar cancer" "vulvar neoplasm" with the Boolean operator "AND".

The reference list of the possible articles was also reviewed in order to find possible missing articles. We selected article on the basis of their relevance and representativeness. We excluded small size cohorts (less than 10 women included) and studies that did not reported their detection rate. We also excluded studies that did not described precisely the location of the SLN detected.

\section{Topographic distribution of SLNs for patients with endometrial cancer}

Table 1 summarizes the SLNs localization in patients reported in the literature. Twenty-seven studies described precisely the location of the SLNs in patients treated for an endometrial cancer. As described by Zuo et al. (29), most SLNs are located on the UPP pathway: obturator and external iliac.

When analyzing the distribution of SLN, results must be considered with caution. Indeed, the specificity of SLN detection in patients with endometrial cancer lies within the multiple possibilities for injecting the tracer. If first reports used "direct site" injection of blue dye, endometrial and cervical injections, and the use of Tc99 and fluorescence ICG have been described since then. Eventually, if most surgeries were initially performed by laparotomy, a large majority of recent studies were performed by laparoscopy. All these parameters are of paramount importance since the learning curve might influence not only the ability of the surgeon to detect a potential SLN in usual location but also its ability to explore para-aortic area to look for another sentinel node (66). Indeed, the analysis of Table 1 shows a great overall number of sentinel nodes located within the para-aortic area. The SENTI-ENDO trial reported by Ballester et al. (67) concluded to the efficiency of the SLN to accurately predict lymph node invasion in patients with early stage endometrial cancer.

\section{Topographic distribution of SLNs for patients with cervical cancer}

Table 2 summarizes the finding of the review of the 
Table 1 SLN locations in patients with endometrial cancer reported in the literature

\begin{tabular}{|c|c|c|c|c|c|c|c|c|c|c|}
\hline $\begin{array}{l}\text { First } \\
\text { author, } \\
\text { year }\end{array}$ & $\begin{array}{l}\text { Study } \\
\text { size/ } \\
\text { number } \\
\text { of SLN }\end{array}$ & $\begin{array}{l}\text { Tracer } \\
\text { used }\end{array}$ & Site of injection & $\begin{array}{l}\text { External } \\
\text { iliac }\end{array}$ & $\begin{array}{l}\text { Inter/ } \\
\text { internal } \\
\text { iliac }\end{array}$ & $\begin{array}{l}\text { Common } \\
\text { iliac }\end{array}$ & Obturator & $\begin{array}{l}\text { Promontory, } \\
\text { presacral }\end{array}$ & Para-aortic & Other \\
\hline $\begin{array}{l}\text { Allameh, } \\
2015 \text { (41) }\end{array}$ & $15 / 15$ & $\mathrm{BD}$ & $\begin{array}{l}\text { Fundus, } \\
\text { subserosal }\end{array}$ & 0 & $\begin{array}{l}6 \\
(40 \%)\end{array}$ & 0 & 8 (53.3\%) & 0 & $1(6.7 \%)$ & 0 \\
\hline $\begin{array}{l}\text { Burke, } \\
1996 \text { (39) }\end{array}$ & $15 / 31$ & $\mathrm{BD}$ & $\begin{array}{l}\text { Triple site, } \\
\text { subserosal }\end{array}$ & 13 (39.4\%) & 0 & $6(18.2 \%)$ & 0 & 0 & 12 (36.4\%) & 0 \\
\hline $\begin{array}{l}\text { Delahoye, } \\
2007 \text { (43) }\end{array}$ & $60 / 180$ & $B D+R T$ & $\begin{array}{l}\text { Hysteroscopy } \\
\text { subendometrial }\end{array}$ & $56(31 \%)$ & $\begin{array}{l}33 \\
(18 \%)\end{array}$ & $30(17 \%)$ & $36(20 \%)$ & 0 & $25(14 \%)$ & 0 \\
\hline $\begin{array}{l}\text { Ferraioli, } \\
2015 \text { (45) }\end{array}$ & $93 / 30$ & $B D+R T$ & Cervical & $21(70 \%)$ & $\begin{array}{l}8 \\
(26.7 \%)\end{array}$ & $1(3.3 \%)$ & 0 & 0 & 0 & 0 \\
\hline $\begin{array}{l}\text { Frumovitz, } \\
2007 \text { (46) }\end{array}$ & $18 / 13$ & $B D+R T$ & $\begin{array}{l}\text { Fundus, } \\
\text { subserosal }\end{array}$ & $3(23.1 \%)$ & 0 & $1(7.7 \%)$ & $3(23.1 \%)$ & 0 & $4(30.8 \%)$ & $2(15.4 \%)$ \\
\hline $\begin{array}{l}\text { Gien, } \\
2005 \text { (47) }\end{array}$ & $16 / 13$ & $\mathrm{BD}+\mathrm{RT}$ & $\begin{array}{l}\text { Hysteroscopy/ } \\
\text { subserosal }\end{array}$ & 7 (53.8\%) & 0 & $3(23.1 \%)$ & $2(15.4 \%)$ & $1(7.7 \%)$ & 0 & 0 \\
\hline $\begin{array}{l}\text { How, } \\
2015 \text { (48) }\end{array}$ & $100 / 288$ & $B D+R T$ & $\begin{array}{l}\text { Submucosal } \\
\text { and deep } \\
\text { stromal cervical }\end{array}$ & $69(24 \%)$ & $\begin{array}{l}57 \\
(19.7 \%)\end{array}$ & - & 148 (52\%) & 0 & $13(4.5 \%)$ & 0 \\
\hline $\begin{array}{l}\text { Niikura, } \\
2013 \text { (52) }\end{array}$ & $100 / 426$ & $B D+R T$ & $\begin{array}{l}\text { Hysteroscopy/ } \\
\text { cervical }\end{array}$ & 115 (27.3\%) & $24(5.7 \%)$ & 29 (6.9\%) & $\begin{array}{l}178 \\
(42.2 \%)\end{array}$ & $4(0.9 \%)$ & 75 (17.8\%) & $\begin{array}{l}1 \\
(0.2 \%)\end{array}$ \\
\hline $\begin{array}{l}\text { Paley, } \\
2016 \text { (53) }\end{array}$ & $123 / 332$ & ICG & Cervical & 167 (49\%) & $16(5 \%)$ & $42(12 \%)$ & $72(21 \%)$ & $5(1.5 \%)$ & $29(8 \%)$ & $\begin{array}{l}\text { Parametrial } \\
1(<1 \%)\end{array}$ \\
\hline $\begin{array}{l}\text { Pandit- } \\
\text { Taskar, } \\
2010 \text { (54) }\end{array}$ & $40 / 78$ & RT & Cervical & $24(30.8 \%)$ & $\begin{array}{l}19 \\
(24.4 \%)\end{array}$ & 19 (24.4\%) & $10(12.8 \%)$ & 0 & $5(6.4 \%)$ & $\begin{array}{l}\text { Parametrial } \\
1(1.3 \%)\end{array}$ \\
\hline $\begin{array}{l}\text { Papadia, } \\
2016(55)\end{array}$ & $75 / \mathrm{NA}$ & ICG & Cervical & $32 \%$ & 0 & $8 \%$ & $55 \%$ & 0 & $5 \%$ & 0 \\
\hline $\begin{array}{l}\text { Pelosi, } \\
2003 \text { (56) }\end{array}$ & 16/NA & $B D+R T$ & Cervical & 0 & $100 \%$ & 0 & 0 & 0 & 0 & 0 \\
\hline
\end{tabular}

Table 1 (continuned) 
Table 1 (continuned)

\begin{tabular}{|c|c|c|c|c|c|c|c|c|c|c|}
\hline $\begin{array}{l}\text { First } \\
\text { author, } \\
\text { year }\end{array}$ & $\begin{array}{l}\text { Study } \\
\text { size/ } \\
\text { number } \\
\text { of SLN }\end{array}$ & $\begin{array}{l}\text { Tracer } \\
\text { used }\end{array}$ & $\begin{array}{l}\text { Site } \\
\text { of injection }\end{array}$ & $\begin{array}{l}\text { External } \\
\text { iliac }\end{array}$ & $\begin{array}{l}\text { Inter/ } \\
\text { internal } \\
\text { iliac }\end{array}$ & $\begin{array}{l}\text { Common } \\
\text { iliac }\end{array}$ & Obturator & $\begin{array}{l}\text { Promontory, } \\
\text { presacral }\end{array}$ & Para-aortic & Other \\
\hline $\begin{array}{l}\text { Raspagliesi, } \\
2004 \text { (57) }\end{array}$ & $18 / 45$ & $\mathrm{BD}+\mathrm{RT}$ & Hysteroscopy & $13(28.9 \%)$ & $2(4.4 \%)$ & $10(22.2 \%)$ & 8 (17.8\%) & & $12(26.7 \%)$ & 0 \\
\hline $\begin{array}{l}\text { Solima, } \\
2012(59)\end{array}$ & $80 / 154$ & $\mathrm{RT}$ & Hysteroscopy & $46(29.9 \%)$ & 0 & 27 (17.5\%) & $\begin{array}{l}48 \\
(31.1 \%)\end{array}$ & 0 & 33 (21.4\%) & 0 \\
\hline $\begin{array}{l}\text { Vidal, } \\
2013(60)\end{array}$ & $66 / 74$ & $\mathrm{BD}$ & Cervical & $6(8.1 \%)$ & $\begin{array}{l}30 \\
(40.5 \%)\end{array}$ & $2(2.7 \%)$ & $\begin{array}{l}19 \\
(25.7 \%)\end{array}$ & 0 & 0 & $\begin{array}{l}\text { Not } \\
\text { defined } \\
17(23 \%)\end{array}$ \\
\hline $\begin{array}{l}\text { Rossi, } \\
2013 \text { (62) }\end{array}$ & $385 / 888$ & ICG & Cervical & 335 (38\%) & $92(10 \%)$ & $68(8 \%)$ & $\begin{array}{l}218 \\
(25 \%)\end{array}$ & $\begin{array}{l}26 \\
(3 \%)\end{array}$ & 139 (15\%) & $\begin{array}{l}\text { Parametrium } \\
10(1 \%)\end{array}$ \\
\hline $\begin{array}{l}\text { Shimada, } \\
2018(63)\end{array}$ & $57 / 114$ & $I C G+R T$ & Cervical & $5(4.4 \%)$ & $\begin{array}{l}36 \\
(31.6 \%)\end{array}$ & $4(3.5 \%)$ & $\begin{array}{l}69 \\
(60.5 \%)\end{array}$ & 0 & 0 & 0 \\
\hline $\begin{array}{l}\text { Mendivil, } \\
2018 \text { (64) }\end{array}$ & $87 / 245$ & ICG & Cervical & $76(31.0 \%)$ & $\begin{array}{l}78 \\
(31.8 \%)\end{array}$ & 0 & $\begin{array}{l}45 \\
(18.4 \%)\end{array}$ & $\begin{array}{l}29 \\
(11.8 \%)\end{array}$ & 17 (6.9\%) & 0 \\
\hline $\begin{array}{l}\text { Ruiz, } \\
2018 \text { (65) }\end{array}$ & $111 / 429$ & ICG & $\begin{array}{l}\text { Cervical and } \\
\text { fundus }\end{array}$ & 70 (16.3\%) & $\begin{array}{l}121 \\
(28.2 \%)\end{array}$ & $23(5.4 \%)$ & $\begin{array}{l}50 \\
(11.7 \%)\end{array}$ & $\begin{array}{l}14 \\
(3.3 \%)\end{array}$ & $151(35.2 \%)$ & 0 \\
\hline $\begin{array}{l}\text { Zuo, } \\
2019 \text { (29) }\end{array}$ & $115 / 515$ & $\begin{array}{l}\text { Carbon } \\
\text { nanoparticle }\end{array}$ & $\begin{array}{l}\text { Cervical and } \\
\text { fundus }\end{array}$ & $229(44.5 \%)$ & $\begin{array}{l}106 \\
(20.6 \%)\end{array}$ & 49 (9.5\%) & $\begin{array}{l}116 \\
(22.5 \%)\end{array}$ & 0 & 15 (2.9\%) & 0 \\
\hline
\end{tabular}

Please note that the figures have been calculated and might not total $100 \%$ and/or match the number of total SLNs as it depended of the figures presented in the studies. The percentage refers to the location of lymph nodes. BD, blue dye; RT, radiotracer; ICG, indocyanine green; NA, not available.

literature describing SLNs locations. Forty-three studies described precisely the sentinel node location. Few studies included more than hundred patients with many reports of relatively "small" size cohorts.

As reported by Marnitz (108), removal of SLN in the external iliac, interiliac and obturator area enables evaluation of more than $80 \%$ of all SLN. This is in accordance with the lymphatic drainage previously described through the lateral parametrium. Furthermore, they showed that the node location was independent of histology and of tumor stage.

These locations of SLNs are consistent with the locations of metastatic lymph nodes in patients that underwent full lymphadenectomy (109). However, in the different studies reviewed, it is of note that the number of SLNs located within the parametrium is low. Considering the pattern of lymphatic dissemination of cervical tumors, we could expect higher number of lymph nodes located in the parametrium. A possible explanation is that the surgeons failed to biopsy some lymph nodes located in the parametrium as they are deeply located and could be difficult to identify and remove especially if the tracer injection within cervix has been inappropriate. Lymph nodes located within the parametrium are of small size and could have been missed by the surgeons, or described as being part of the obturator fossa.

\section{Topographic distribution of SLNs for patients with vulvar cancer}

In most cases, the SLN will be found just below Camper's fascia but its position can sometimes vary within the Femoral triangle. As mentioned by Frumovitz et al. (110), patients with clitoral lesions can have short afferent lymph 
Table 2 SLN locations in patients with cervical cancer reported in the literature

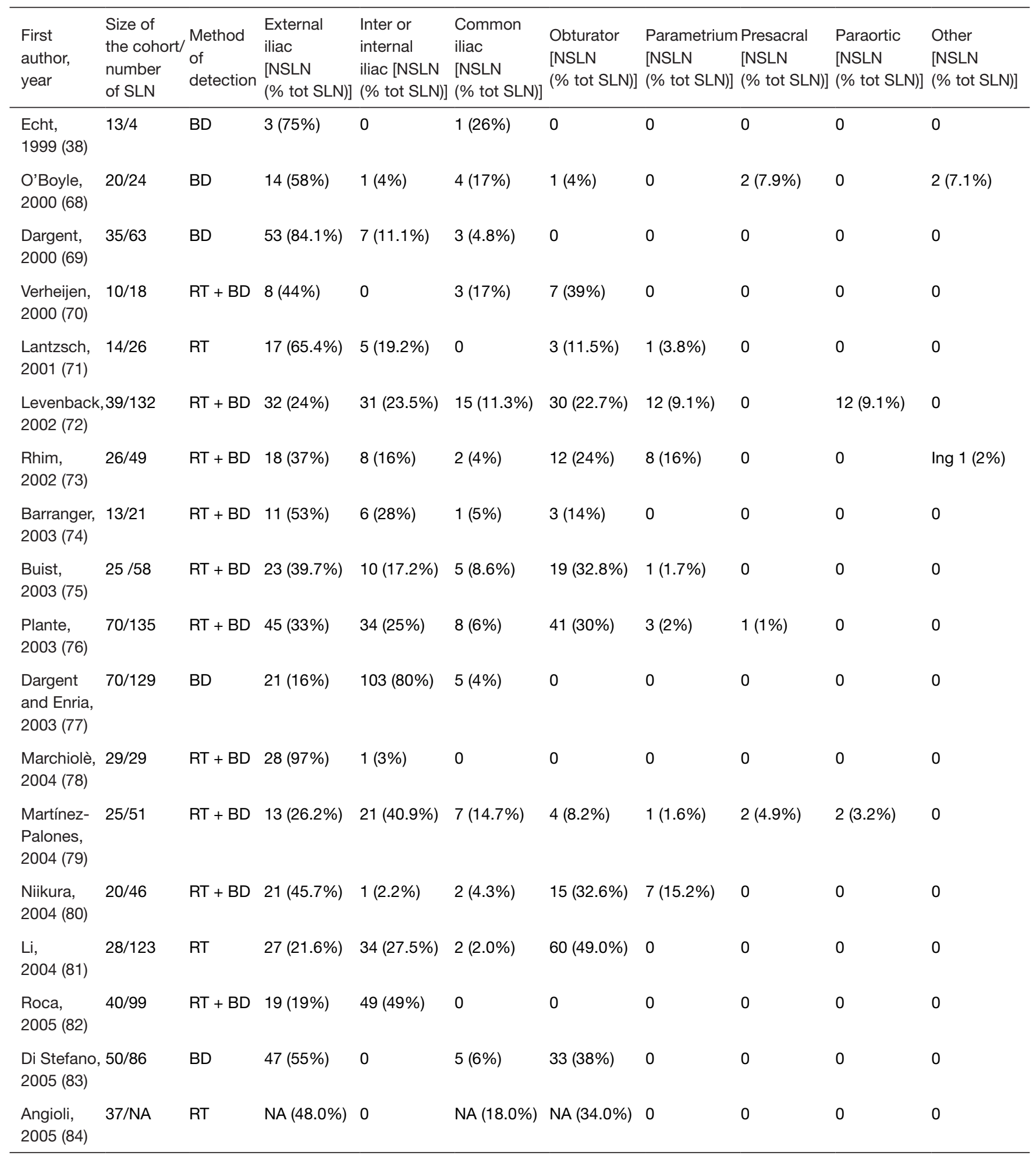

Table 2 (continuned) 
Table 2 (continuned)

\begin{tabular}{|c|c|c|c|c|c|c|c|c|c|c|}
\hline $\begin{array}{l}\text { First } \\
\text { author, } \\
\text { year }\end{array}$ & $\begin{array}{l}\text { First } \\
\text { author, } \\
\text { year }\end{array}$ & $\begin{array}{l}\text { Method } \\
\text { of } \\
\text { detection }\end{array}$ & $\begin{array}{l}\text { External } \\
\text { iliac } \\
\text { [NSLN } \\
\text { (\% tot SLN)] }\end{array}$ & $\begin{array}{l}\text { Inter or } \\
\text { internal } \\
\text { iliac [NSLN } \\
\text { (\% tot SLN)] }\end{array}$ & $\begin{array}{l}\text { Common } \\
\text { iliac } \\
\text { [NSLN } \\
\text { (\% tot SLN)] }\end{array}$ & $\begin{array}{l}\text { Obturator } \\
\text { [NSLN } \\
(\% \text { tot SLN)] }\end{array}$ & $\begin{array}{l}\text { Parametrium } \\
\text { [NSLN } \\
(\% \text { tot SLN)] }\end{array}$ & $\begin{array}{l}\text { n Presacral } \\
{[N S L N} \\
(\% \text { tot SLN)] }\end{array}$ & $\begin{array}{l}\text { Paraortic } \\
\text { [NSLN } \\
\text { (\% tot SLN)] }\end{array}$ & $\begin{array}{l}\text { Other } \\
\text { [NSLN } \\
(\% \text { tot SLN)] }\end{array}$ \\
\hline $\begin{array}{l}\text { Silva, } \\
2005 \text { (85) }\end{array}$ & $56 / 120$ & $\mathrm{RT}$ & $53(44.2 \%)$ & $10(8.3 \%)$ & $8(6.7 \%)$ & 47 (39.2\%) & $1(0.8 \%)$ & 0 & $1(0.8 \%)$ & 0 \\
\hline $\begin{array}{l}\text { Rob, } \\
2005 \text { (86) }\end{array}$ & $183 / 462$ & $\mathrm{RT}+\mathrm{BD}$ & 208 (45\%) & 0 & $22(4.8 \%)$ & 197 (42.6\%) & $14(3 \%)$ & $21(4.6 \%)$ & 0 & 0 \\
\hline $\begin{array}{l}\text { Lin, } \\
2005 \text { (87) }\end{array}$ & $30 / 121$ & RT & $17(14 \%)$ & $39(32 \%)$ & $19(16 \%)$ & 46 (38\%) & 0 & 0 & 0 & 0 \\
\hline $\begin{array}{l}\text { Gil- } \\
\text { Moreno, } \\
2005 \text { (88) }\end{array}$ & $12 / 21$ & $R T+B D$ & $4(19 \%)$ & $12(57 \%)$ & $1(5 \%)$ & $3(14 \%)$ & 0 & $1(5 \%)$ & 0 & 0 \\
\hline $\begin{array}{l}\text { Hauspy, } \\
2007 \text { (90) }\end{array}$ & $39 / \mathrm{NA}$ & $\mathrm{RT}+\mathrm{BD}$ & NA (19\%) & NA (3.7\%) & NA (9.5\%) & NA (67.2\%) & 0 & 0 & $\mathrm{NA}(0.5 \%)$ & 0 \\
\hline $\begin{array}{l}\text { Kushner, } \\
2007 \text { (91) }\end{array}$ & $20 / 64$ & $\mathrm{RT}+\mathrm{BD}$ & $19(30 \%)$ & 12 (19\%) & $7(11 \%)$ & $21(33 \%)$ & 0 & $3(5 \%)$ & $2(3 \%)$ & 0 \\
\hline $\begin{array}{l}\text { Yuan, } \\
2007 \text { (92) }\end{array}$ & $81 / 192$ & $\mathrm{BD}$ & 39 (20.1\%) & 34 (17.8\%) & 34 (17.8\%) & $83(43.2 \%)$ & $1(0.6 \%)$ & 0 & 0 & $\begin{array}{l}\text { Ing. } 1 \\
(0.6 \%)\end{array}$ \\
\hline $\begin{array}{l}\text { Seong, } \\
2007 \text { (93) }\end{array}$ & $89 / 83$ & $\mathrm{BD}$ & 49 (59.0\%) & 9 (10.8\%) & $1(1.2 \%)$ & 24 (28.9\%) & 0 & 0 & 0 & 0 \\
\hline $\begin{array}{l}\text { Lee, } \\
2007 \text { (94) }\end{array}$ & $57 / 123$ & $\mathrm{RT}+\mathrm{BD}$ & 64 (51.9\%) & $3(2.5 \%)$ & $12(10.1 \%)$ & 25 (20.3\%) & $3(2.5 \%)$ & 0 & 0 & $\begin{array}{l}\text { Ing. } 3 \\
(2.5 \%)\end{array}$ \\
\hline $\begin{array}{l}\text { Acharya, } \\
2009 \text { (98) }\end{array}$ & $30 / 60$ & $\mathrm{BD}$ & 19 (31.7\%) & $5(8.3 \%)$ & 0 & $30(50 \%)$ & $6(10 \%)$ & 0 & 0 & 0 \\
\hline $\begin{array}{l}\text { Fotiou, } \\
2010 \text { (99) }\end{array}$ & $42 / 103$ & $\mathrm{RT}+\mathrm{BD}$ & 37 (35.9\%) & $21(20.5 \%)$ & $5(5.1 \%)$ & 37 (35.9\%) & 0 & 0 & $3(2.6 \%)$ & 0 \\
\hline $\begin{array}{l}\text { Ogawa, } \\
2010 \text { (100) }\end{array}$ & $82 / 157$ & RT & 57 (36.4\%) & $12(7.8 \%)$ & $5(3.2 \%)$ & $80(50.6 \%)$ & $1(0.6 \%)$ & & & \\
\hline $\begin{array}{l}\text { Kato, } \\
2011 \text { (101) }\end{array}$ & $50 / 102$ & RT & $5(5.3 \%)$ & $11(10.5 \%)$ & $6(6.3 \%)$ & 73 (71.6\%) & $6(6.3 \%)$ & 0 & 0 & 0 \\
\hline $\begin{array}{l}\text { Roy, } \\
2011 \text { (102) }\end{array}$ & 211/NA & $\mathrm{RT}+\mathrm{BD}$ & 0 & NA (85.6\%) & 0 & NA (16.7\%) & 0 & 0 & NA (3.8\%) & 0 \\
\hline $\begin{array}{l}\text { Lécuru, } \\
2011 \text { (103) }\end{array}$ & $139 / 263$ & $\mathrm{RT}+\mathrm{BD}$ & 212 (80.6\%) & & 0 & 0 & 0 & 0 & 0 & 0 \\
\hline
\end{tabular}

Table 2 (continuned) 
Table 2 (continuned)

\begin{tabular}{|c|c|c|c|c|c|c|c|c|c|c|}
\hline $\begin{array}{l}\text { First } \\
\text { author, } \\
\text { year }\end{array}$ & $\begin{array}{l}\text { Size of the } \\
\text { cohort/ } \\
\text { number } \\
\text { of SLN }\end{array}$ & $\begin{array}{l}\text { Method } \\
\text { of } \\
\text { detection }\end{array}$ & $\begin{array}{l}\text { External } \\
\text { iliac } \\
\text { [NSLN } \\
\text { (\% tot SLN)] }\end{array}$ & $\begin{array}{l}\text { Inter or } \\
\text { internal } \\
\text { iliac [NSLN } \\
\text { (\% tot SLN)] }\end{array}$ & $\begin{array}{l}\text { Common } \\
\text { iliac [NSLN } \\
\text { (\% tot SLN)] }\end{array}$ & $\begin{array}{l}\text { Obturator } \\
\text { [NSLN } \\
(\% \text { tot SLN)] }\end{array}$ & $\begin{array}{l}\text { Parametrium } \\
\text { [NSLN } \\
(\% \text { tot SLN)] }\end{array}$ & $\begin{array}{l}\text { Presacral } \\
\text { [NSLN } \\
(\% \text { tot SLN)] }\end{array}$ & $\begin{array}{l}\text { Paraortic } \\
\text { [NSLN } \\
(\% \text { tot SLN)] }\end{array}$ & $\begin{array}{l}\text { Other } \\
\text { [NSLN } \\
(\% \text { tot SLN)] }\end{array}$ \\
\hline $\begin{array}{l}\text { Díaz- } \\
\text { Feijoo, } \\
2011 \text { (104) }\end{array}$ & $22 / 57$ & $\mathrm{RT}+\mathrm{BD}$ & $3(5.7 \%)$ & 31 (54.7\%) & $6(11.3 \%)$ & $16(28.3 \%)$ & 0 & 0 & 0 & 0 \\
\hline $\begin{array}{l}\text { Zhang, } \\
2014 \text { (106) }\end{array}$ & $56 / 106$ & $\mathrm{BD}$ & 30 (28.3\%) & 26 (24.5\%) & $3(2.8 \%)$ & 42 (39.6\%) & 0 & 0 & 0 & $\begin{array}{l}\text { Ing. } 5 \\
(4.7 \%)\end{array}$ \\
\hline $\begin{array}{l}\text { Kim, } \\
2018 \text { (107) }\end{array}$ & $103 / 241$ & ICG & 84 (34.9\%) & $9(3.7 \%)$ & $6(2.5 \%)$ & $131(54.4 \%)$ & $9(3.7 \%)$ & $1(0.4 \%)$ & $1(0.4 \%)$ & 0 \\
\hline
\end{tabular}

Please note that the figures have been calculated and might not total $100 \%$ and/or match the number of total SLNs as it depended of the figures presented in the studies. BD, blue dye; RT, radiotracer; ICG, indocyanine green; Ing, inguinal; NA, not available; NSLN, number of sentinel lymph nodes; \% tot SLN, percentage of total sentinel lymph nodes.

channels with sentinel nodes often located in a very medial location just lateral to the adductor longus muscle (111). In such cases, surgeons could be helped by combining detection technics to effectively reduce the risk of SLN failure $(112,113)$.

Lymph node procedure has become a key step of gynecologic cancers surgical staging. The knowledge of lymphatic anatomical pathways is therefore mandatory for oncogynecologic surgeons. Here we presented lymphatic drainage according to the type of gynecologic cancer. We also reviewed the topographic distribution rate of SLNs in each of these cancers. These data are important since it can help surgeons reduce both their rate of SLN detection failure and their rate of false negative (non-sentinel nodes).

With the generalization of SLN procedure in patients with endometrial cancer, knowing the usual distribution of the sentinel node is of determinant. Persson et al. developed a surgical algorithm to maximize the detection of SLNs (114). Surgeons performing endometrial cancer surgery should be trained to limit failure in lymph nodes detection (115). This is all the more important that it can prevent patients with pre-operative intermediate risk (and sometimes even high risk ESMO) from a secondary staging surgery including pelvic and para-aortic lymphadenectomy, much more at risk of short and long term complications and that could delay adjuvant therapies. An interesting point that is insufficiently reported is the number of SLN positive by localization. Zuo et al. (29) reported in 2018 a study that aimed to evaluate the detection rate and accuracy of SLN mapping using cervical and fundal injection of carbon nanoparticles in patients with endometrial cancer. They found in the group of patients that had fundal injection that metastatic lymph nodes were located in the right external iliac (2/36), left external iliac (1/30) and right internal iliac $(1 / 11)$ with no other metastasis especially in the paraaortic area. In the group of patients that benefited of a cervical injection, metastatic lymph nodes were located in the right external iliac (3/81), right common iliac (1/19), left external iliac (1/82), left internal iliac (1/38), left obturator (1/46), right obturator (1/52). Knowing the proportion of metastatic SLN per location could be helpful for surgeons since failure to identify SLN in these specific areas could lead to immediate lymphadenectomy.

In patients with early stage cervical cancer, the morbidity of radical hysterectomy, i.e., with resection of the parametrium is currently being questioned as in selected patients, the risk of parametrial invasion is almost null (116-118). An option discussed by many authors is a two-steps procedure by performing a conization and SLN procedure to elect whether extension to the parametrium is mandatory. If a nonsignificant proportion of SLNs should be located within the parametrium, surgeons should make sure to identify correctly 
those to remove them.

Anatomical basis of SLN for patients with vulvar cancer are less subject to discussion. As previously mentioned, the several surgical amendments that have been developed since the initial description of the surgery contributed to reduce postoperative morbidity in patients undergoing full lymphadenectomy (111). For example, Saphenous vein sparing improves postoperative outcomes in patients following inguino femoral lymphadenectomy (119). While progressive implementation of SLN in vulvar cancer decreased the risk of lower limb lymphedema by 10 fold, factors associated with secondary morbidity are less described (120). As vulvar cancer are rare, such patients should be managed in experienced centers all the more a learning curve is non-negligible in finding the SLN (121). In the setting of vulvar carcinoma, surgeons benefit from the low anatomical variation of this area located within the femoral triangle.

Our study suffers from some limitations. We made the choice to exclude studies that were not precise enough to describe location of the SLN. By doing so, we excluded large scaled studies, including the SENTI ENDO trial that was a major step toward incorporating SLN procedure into daily practice in expert centers. We searched only PubMed and not included other databases, we excluded studies non-English written. Eventually, while some clinicians are currently studying how SLN could be part of ovarian cancer patients management, we voluntarily excluded this malignancy from the review until more solid data is available $(122,123)$.

\section{Conclusions}

The understanding of the anatomical basis underlying the research for SLNs is important. In particular, endometrial and cervical cancers do not have the same patterns of dissemination. As so, surgeons should be cautious when performing SLN research, especially in the parametrium area in patients with cervical cancer and in the paraaortic area in patients with endometrial cancer. Surgical training is a key step toward improving detection rates and exhaustiveness of SLN research while reducing overall morbidity.

\section{Acknowledgments}

Funding: None.

\section{Footnote}

Provenance and Peer Review: This article was commissioned by the editorial office, Chinese Clinical Oncology for the series "Sentinel Lymph Node Biopsy in Gynecologic Cancer". The article was sent for external peer review.

Conflicts of Interest: The authors have completed the ICMJE uniform disclosure form (available at http://dx.doi. org/10.21037/cco-20-228). The series "Sentinel Lymph Node Biopsy in Gynecologic Cancer" was commissioned by the editorial office without any funding or sponsorship. Drs. DQ and CA served as the unpaid Guest Editors of the series. Dr. DQ serves as an unpaid editorial board member of Chinese Clinical Oncology from Dec 2019 to Dec 2021. Dr. CT reports personal fees from Astra Zeneca, personal fees from MSD, personal fees from Conmed, personal fees from AB Medica, personal fees from TBWA Adelphi, outside the submitted work. The authors have no other conflicts of interest to declare.

Ethical Statement: The authors are accountable for all aspects of the work in ensuring that questions related to the accuracy or integrity of any part of the work are appropriately investigated and resolved.

Open Access Statement: This is an Open Access article distributed in accordance with the Creative Commons Attribution-NonCommercial-NoDerivs 4.0 International License (CC BY-NC-ND 4.0), which permits the noncommercial replication and distribution of the article with the strict proviso that no changes or edits are made and the original work is properly cited (including links to both the formal publication through the relevant DOI and the license). See: https://creativecommons.org/licenses/by-nc-nd/4.0/.

\section{References}

1. Kim SI, Lim MC, Lee JS, et al. Impact of lower limb lymphedema on quality of life in gynecologic cancer survivors after pelvic lymph node dissection. Eur J Obstet Gynecol Reprod Biol 2015;192:31-6.

2. Hayes SC, Janda M, Ward LC, et al. Lymphedema following gynecological cancer: Results from a prospective, longitudinal cohort study on prevalence, incidence and risk factors. Gynecol Oncol 2017;146:623-9.

3. Franchi M, Ghezzi F, Riva C, et al. Postoperative complications after pelvic lymphadenectomy for the 
surgical staging of endometrial cancer. J Surg Oncol 2001;78:232-7; discussion 237-40.

4. Stehman FB, Bundy BN, Dvoretsky PM, et al. Early stage I carcinoma of the vulva treated with ipsilateral superficial inguinal lymphadenectomy and modified radical hemivulvectomy: a prospective study of the Gynecologic Oncology Group. Obstet Gynecol 1992;79:490-7.

5. de Hullu JA, Ansink AC, Tymstra T, et al. What doctors and patients think about false-negative sentinel lymph nodes in vulvar cancer. J Psychosom Obstet Gynaecol 2001;22:199-203.

6. Rouzier R, Haddad B, Dubernard G, et al. Inguinofemoral dissection for carcinoma of the vulva: effect of modifications of extent and technique on morbidity and survival. J Am Coll Surg 2003;196:442-50.

7. Gaarenstroom KN, Kenter GG, Trimbos JB, et al. Postoperative complications after vulvectomy and inguinofemoral lymphadenectomy using separate groin incisions. Int J Gynecol Cancer 2003;13:522-7.

8. Morrow CP, Bundy BN, Kurman RJ, et al. Relationship between surgical-pathological risk factors and outcome in clinical stage I and II carcinoma of the endometrium: a Gynecologic Oncology Group study. Gynecol Oncol 1991;40:55-65.

9. Creasman WT, Kohler MF. Is lymph vascular space involvement an independent prognostic factor in early cervical cancer? Gynecol Oncol 2004;92:525-9.

10. Biewenga P, van der Velden J, Mol BWJ, et al. Prognostic model for survival in patients with early stage cervical cancer. Cancer 2011;117:768-76.

11. Macdonald OK, Chen J, Dodson M, et al. Prognostic significance of histology and positive lymph node involvement following radical hysterectomy in carcinoma of the cervix. Am J Clin Oncol 2009;32:411-6.

12. Havrilesky LJ, Leath CA, Huh W, et al. Radical hysterectomy and pelvic lymphadenectomy for stage IB2 cervical cancer. Gynecol Oncol 2004;93:429-34.

13. Hacker NF, Berek JS, Lagasse LD, et al. Management of regional lymph nodes and their prognostic influence in vulvar cancer. Obstet Gynecol 1983;61:408-12.

14. Balega J, Van Trappen PO. The sentinel node in gynaecological malignancies. Cancer Imaging 2006;6:7-15.

15. Gould EA, Winship T, Philbin PH, et al. Observations on a 'sentinel node' in cancer of the parotid. Cancer 1960;13:77-8.

16. Cabanas RM. An approach for the treatment of penile carcinoma. Cancer 1977;39:456-66.

17. Morton DL, Wen DR, Wong JH, et al. Technical details of intraoperative lymphatic mapping for early stage melanoma. Arch Surg Chic Ill 1960 1992;127:392-9.

18. Giuliano AE, Kirgan DM, Guenther JM, et al. Lymphatic mapping and sentinel lymphadenectomy for breast cancer. Ann Surg 1994;220:391-8; discussion 398-401.

19. Weiser EB, Bundy BN, Hoskins WJ, et al. Extraperitoneal versus transperitoneal selective Para-aortic lymphadenectomy in the pretreatment surgical staging of advanced cervical carcinoma (a Gynecologic Oncology Group study). Gynecol Oncol 1989;33:283-9.

20. Grigsby PW. Radiotherapy for pelvic recurrence after radical hysterectomy for cervical cancer. Radiat Med 2005;23:327-30.

21. Denschlag D, Gabriel B, Mueller-Lantzsch C, et al. Evaluation of patients after extraperitoneal lymph node dissection for cervical cancer. Gynecol Oncol 2005;96:658-64.

22. Cibula D, Pötter R, Planchamp F, et al. The European Society of Gynaecological Oncology/European Society for Radiotherapy and Oncology/European Society of Pathology guidelines for the management of patients with cervical cancer. Radiother Oncol 2018;127:404-16.

23. Colombo N, Creutzberg C, Amant F, et al. ESMOESGO-ESTRO Consensus Conference on Endometrial Cancer: Diagnosis, Treatment and Follow-up. Int J Gynecol Cancer 2016;26:2-30.

24. National Comprehensive Cancer Network. Version 2.2020 2020. Available online: https://www.nccn.org/ professionals/physician_gls/pdf/uterine.pdf

25. Oonk MHM, Planchamp F, Baldwin P, et al. European Society of Gynaecological Oncology Guidelines for the Management of Patients With Vulvar Cancer. Int J Gynecol Cancer 2017;27:832-7.

26. Reiffenstuhl: The lymphatics of the female genital organs - Google Scholar. Available online: https://scholar.google. com/scholar_lookup?title=The $\%$ 20lymphatics $\% 20$ of $\% 20$ the $\% 20$ female $\% 20$ genital\%20organs\&author=G. $\% 20$ Reiffenstuhl\&publication_year=1964\#d=gs_cit\&u=\%2 Fscholar\%3Fq\%3Dinfo\%3AhjddrFk0ocgJ\%3Ascholar. google.com\%2F\%26output\%3Dcite\%26scirp\%3D0\%26 hl\%3Dfr

27. Plentl AA, Friedman EA. Lymphatic system of the female genitalia. The morphologic basis of oncologic diagnosis and therapy. Major Probl Obstet Gynecol 1971;2:1-223.

28. Geppert B, Lönnerfors C, Bollino M, et al. A study on uterine lymphatic anatomy for standardization of pelvic sentinel lymph node detection in endometrial cancer. Gynecol Oncol 2017;145:256-61. 
29. Zuo J, Wu LY, Cheng M, et al. Comparison Study of Laparoscopic Sentinel Lymph Node Mapping in Endometrial Carcinoma Using Carbon Nanoparticles and Lymphatic Pathway Verification. J Minim Invasive Gynecol 2019;26:1125-32.

30. Benedetti-Panici P, Maneschi F, D'Andrea G, et al. Early cervical carcinoma: the natural history of lymph node involvement redefined on the basis of thorough parametrectomy and giant section study. Cancer 2000;88:2267-74.

31. Girardi F, Lichtenegger W, Tamussino K, et al. The importance of parametrial lymph nodes in the treatment of cervical cancer. Gynecol Oncol 1989;34:206-11.

32. Bonneau C, Cortez A, Lis R, et al. Lymphatic and nerve distribution throughout the parametrium. Gynecol Oncol 2013;131:708-13.

33. Parry-Jones E. Lymphatics of the vulva. J Obstet Gynaecol Br Commonw 1963;70:751-65.

34. Iversen T, Aas M. Lymph drainage from the vulva. Gynecol Oncol 1983;16:179-89.

35. Borgno G, Micheletti L, Barbero M, et al. Topographic distribution of groin lymph nodes. A study of 50 female cadavers. J Reprod Med 1990;35:1127-9.

36. DiSaia PJ. What is the proper extent of an inguinal lymphadenectomy for early vulvar cancer? Gynecol Oncol 2003;90:687-8; author reply 689-90.

37. Hudson CN, Shulver H, Lowe DC. The surgery of 'inguino-femoral' lymph nodes: is it adequate or excessive? Int J Gynecol Cancer 2004;14:841-5.

38. Echt ML, Finan MA, Hoffman MS, et al. Detection of sentinel lymph nodes with lymphazurin in cervical, uterine, and vulvar malignancies. South Med J 1999;92:204-8.

39. Burke TW, Levenback C, Tornos C, et al. Intraabdominal lymphatic mapping to direct selective pelvic and Paraaortic lymphadenectomy in women with high-risk endometrial cancer: results of a pilot study. Gynecol Oncol 1996;62:169-73.

40. Levenback C, Burke TW, Gershenson DM, et al. Intraoperative lymphatic mapping for vulvar cancer. Obstet Gynecol 1994;84:163-7.

41. Allameh T, Hashemi V, Mohammadizadeh F, et al. Sentinel lymph node mapping in early stage of endometrial and cervical cancers. J Res Med Sci 2015;20:169-73.

42. Bats AS, Clément D, Larousserie F, et al. Does sentinel node biopsy improve the management of endometrial cancer? Data from 43 patients. J Surg Oncol 2008;97:141-5.

43. Delaloye JF, Pampallona S, Chardonnens E, et al. Intraoperative lymphatic mapping and sentinel node biopsy using hysteroscopy in patients with endometrial cancer. Gynecol Oncol 2007;106:89-93.

44. Favero G, Pfiffer T, Ribeiro A, et al. Laparoscopic sentinel lymph node detection after hysteroscopic injection of technetium-99 in patients with endometrial cancer. Int J Gynecol Cancer 2015;25:423-30.

45. Ferraioli D, Chopin N, Beurrier F, et al. The incidence and clinical significance of the micrometastases in the sentinel lymph nodes during surgical staging for early endometrial cancer. Int J Gynecol Cancer 2015;25:673-80.

46. Frumovitz M, Bodurka DC, Broaddus RR, et al. Lymphatic mapping and sentinel node biopsy in women with high-risk endometrial cancer. Gynecol Oncol 2007;104:100-3.

47. Gien LT, Kwon JS, Carey MS. Sentinel Node Mapping With Isosulfan Blue Dye in Endometrial Cancer. J Obstet Gynaecol Can 2005;27:1107-12.

48. How J, Gotlieb WH, Press JZ, et al. Comparing indocyanine green, technetium, and blue dye for sentinel lymph node mapping in endometrial cancer. Gynecol Oncol 2015;137:436-42.

49. Kadkhodayan S, Shiravani Z, Hasanzadeh M, et al. Lymphatic mapping and sentinel node biopsy in endometrial cancer - a feasibility study using cervical injection of radiotracer and blue dye. Nucl Med Rev Cent East Eur 2014;17:55-8.

50. Lopes LA, Nicolau SM, Baracat FF, et al. Sentinel lymph node in endometrial cancer. Int J Gynecol Cancer 2007;17:1113-7.

51. López-De la Manzanara Cano C, Cordero García JM, Martín-Francisco C, et al. Sentinel lymph node detection using 99m Tc combined with methylene blue cervical injection for endometrial cancer surgical management: a prospective study. Int J Gynecol Cancer 2014;24:1048-53.

52. Niikura H, Kaiho-Sakuma M, Tokunaga H, et al. Tracer injection sites and combinations for sentinel lymph node detection in patients with endometrial cancer. Gynecol Oncol 2013;131:299-303.

53. Paley PJ, Veljovich DS, Press JZ, et al. A prospective investigation of fluorescence imaging to detect sentinel lymph nodes at robotic-assisted endometrial cancer staging. Am J Obstet Gynecol 2016;215:117.e1-e7.

54. Pandit-Taskar N, Gemignani ML, Lyall A, et al. Single photon emission computed tomography SPECTCT improves sentinel node detection and localization in cervical and uterine malignancy. Gynecol Oncol 2010;117:59-64.

55. Papadia A, Imboden S, Siegenthaler F, et al. Laparoscopic 
Indocyanine Green Sentinel Lymph Node Mapping in Endometrial Cancer. Ann Surg Oncol 2016;23:2206-11.

56. Pelosi E, Arena V, Baudino B, et al. Pre-operative lymphatic mapping and intra-operative sentinel lymph node detection in early stage endometrial cancer. Nucl Med Commun 2003;24:971-5.

57. Raspagliesi F, Ditto A, Kusamura S, et al. Hysteroscopic injection of tracers in sentinel node detection of endometrial cancer: a feasibility study. Am J Obstet Gynecol 2004;191:435-9.

58. Robova H, Charvat M, Strnad P, et al. Lymphatic mapping in endometrial cancer: comparison of hysteroscopic and subserosal injection and the distribution of sentinel lymph nodes. Int J Gynecol Cancer 2009;19:391-4.

59. Solima E, Martinelli F, Ditto A, et al. Diagnostic accuracy of sentinel node in endometrial cancer by using hysteroscopic injection of radiolabeled tracer. Gynecol Oncol 2012;126:419-23.

60. Vidal F, Leguevaque P, Motton S, et al. Evaluation of the sentinel lymph node algorithm with blue dye labeling for early-stage endometrial cancer in a multicentric setting. Int J Gynecol Cancer 2013;23:1237-43.

61. Perrone AM, Casadio P, Formelli G, et al. Cervical and hysteroscopic injection for identification of sentinel lymph node in endometrial cancer. Gynecol Oncol 2008;111:62-7.

62. Rossi EC, Jackson A, Ivanova A, et al. Detection of sentinel nodes for endometrial cancer with robotic assisted fluorescence imaging: cervical versus hysteroscopic injection. Int J Gynecol Cancer 2013;23:1704-11.

63. Shimada C, Todo Y, Yamazaki H, et al. A feasibility study of sentinel lymph node mapping by cervical injection of a tracer in Japanese women with early stage endometrial cancer. Taiwan J Obstet Gynecol 2018;57:541-5.

64. Mendivil AA, Abaid LN, Brown JV, et al. The safety and feasibility of minimally invasive sentinel lymph node staging using indocyanine green in the management of endometrial cancer. Eur J Obstet Gynecol Reprod Biol 2018;224:29-32.

65. Ruiz R, Gorostidi M, Jaunarena I, et al. Sentinel Node Biopsy in Endometrial Cancer With Dual Cervical and Fundal Indocyanine Green Injection. Int J Gynecol Cancer 2018;28:139-44.

66. Van Oostrum NHM, Makar APH, Van Den Broecke R. Sentinel node procedures in gynecologic cancers: an overview. Acta Obstet Gynecol Scand 2012;91:174-81.

67. Ballester M, Dubernard G, Lécuru F, et al. Detection rate and diagnostic accuracy of sentinel-node biopsy in early stage endometrial cancer: a prospective multicentre study
(SENTI-ENDO). Lancet Oncol 2011;12:469-76.

68. O’Boyle JD, Coleman RL, Bernstein SG, et al. Intraoperative lymphatic mapping in cervix cancer patients undergoing radical hysterectomy: A pilot study. Gynecol Oncol 2000;79:238-43.

69. Dargent D, Martin X, Mathevet P. Laparoscopic assessment of the sentinel lymph node in early stage cervical cancer. Gynecol Oncol 2000;79:411-5.

70. Verheijen RH, Pijpers R, van Diest PJ, et al. Sentinel node detection in cervical cancer. Obstet Gynecol 2000;96:135-8.

71. Lantzsch T, Wolters M, Grimm J, et al. Sentinel node procedure in Ib cervical cancer: a preliminary series. Br J Cancer 2001;85:791-4.

72. Levenback C, Coleman RL, Burke TW, et al. Lymphatic mapping and sentinel node identification in patients with cervix cancer undergoing radical hysterectomy and pelvic lymphadenectomy. J Clin Oncol 2002;20:688-93.

73. Rhim CC, Park JS, Bae SN, et al. Sentinel node biopsy as an indicator for pelvic nodes dissection in early stage cervical cancer. J Korean Med Sci 2002;17:507-11.

74. Barranger E, Grahek D, Cortez A, et al. Laparoscopic sentinel lymph node procedure using a combination of patent blue and radioisotope in women with cervical carcinoma. Cancer 2003;97:3003-9.

75. Buist MR, Pijpers RJ, van Lingen A, et al. Laparoscopic detection of sentinel lymph nodes followed by lymph node dissection in patients with early stage cervical cancer. Gynecol Oncol 2003;90:290-6.

76. Plante M, Renaud MC, Têtu B, et al. Laparoscopic sentinel node mapping in early-stage cervical cancer. Gynecol Oncol 2003;91:494-503.

77. Dargent D, Enria R. Laparoscopic assessment of the sentinel lymph nodes in early cervical cancer. Technique-preliminary results and future developments. Crit Rev Oncol Hematol 2003;48:305-10.

78. Marchiolè P, Buénerd A, Scoazec J-Y, et al. Sentinel lymph node biopsy is not accurate in predicting lymph node status for patients with cervical carcinoma. Cancer 2004;100:2154-9.

79. Martínez-Palones JM, Gil-Moreno A, Pérez-Benavente MA, et al. Intraoperative sentinel node identification in early stage cervical cancer using a combination of radiolabeled albumin injection and isosulfan blue dye injection. Gynecol Oncol 2004;92:845-50.

80. Niikura H, Okamura C, Akahira J, et al. Sentinel lymph node detection in early cervical cancer with combination 99m Tc phytate and patent blue. Gynecol Oncol 2004;94:528-32. 
81. Li B, Zhang W, Liu L, et al. Sentinel lymph node identification in patients with early stage cervical cancer undergoing radical hysterectomy and pelvic lymphadenectomy. Chin Med J (Engl) 2004;117:867-70.

82. Roca I, Caresia AP, Gil-Moreno A, et al. Usefulness of sentinel lymph node detection in early stages of cervical cancer. Eur J Nucl Med Mol Imaging 2005;32:1210-6.

83. Di Stefano AB, Acquaviva G, Garozzo G, et al. Lymph node mapping and sentinel node detection in patients with cervical carcinoma: a 2-year experience. Gynecol Oncol 2005;99:671-9.

84. Angioli R, Palaia I, Cipriani C, et al. Role of sentinel lymph node biopsy procedure in cervical cancer: a critical point of view. Gynecol Oncol 2005;96:504-9.

85. Silva LB, Silva-Filho AL, Traiman P, et al. Sentinel node detection in cervical cancer with $(99 \mathrm{~m}) \mathrm{Tc}$-phytate. Gynecol Oncol 2005;97:588-95.

86. Rob L, Strnad P, Robova H, et al. Study of lymphatic mapping and sentinel node identification in early stage cervical cancer. Gynecol Oncol 2005;98:281-8.

87. Lin YS, Tzeng CC, Huang KF, et al. Sentinel node detection with radiocolloid lymphatic mapping in early invasive cervical cancer. Int J Gynecol Cancer 2005;15:273-7.

88. Gil-Moreno A, Díaz-Feijoo B, Roca I, et al. Total laparoscopic radical hysterectomy with intraoperative sentinel node identification in patients with early invasive cervical cancer. Gynecol Oncol 2005;96:187-93.

89. Wydra D, Sawicki S, Wojtylak S, et al. Sentinel node identification in cervical cancer patients undergoing transperitoneal radical hysterectomy: a study of 100 cases. Int J Gynecol Cancer 2006;16:649-54.

90. Hauspy J, Beiner M, Harley I, et al. Sentinel lymph nodes in early stage cervical cancer. Gynecol Oncol 2007;105:285-90.

91. Kushner DM, Connor JP, Wilson MA, et al. Laparoscopic sentinel lymph node mapping for cervix cancer--a detailed evaluation and time analysis. Gynecol Oncol 2007;106:507-12.

92. Yuan SH, Xiong Y, Wei M, et al. Sentinel lymph node detection using methylene blue in patients with early stage cervical cancer. Gynecol Oncol 2007;106:147-52.

93. Seong SJ, Park H, Yang KM, et al. Detection of sentinel lymph nodes in patients with early stage cervical cancer. J Korean Med Sci 2007;22:105-9.

94. Lee YS, Rhim CC, Lee HN, et al. HPV status in sentinel nodes might be a prognostic factor in cervical cancer. Gynecol Oncol 2007;105:351-7.
95. Kara PP, Ayhan A, Caner B, et al. Sentinel lymph node detection in early stage cervical cancer: a prospective study comparing preoperative lymphoscintigraphy, intraoperative gamma probe, and blue dye. Ann Nucl Med 2008;22:487-94.

96. Fader AN, Edwards RP, Cost M, et al. Sentinel lymph node biopsy in early-stage cervical cancer: utility of intraoperative versus postoperative assessment. Gynecol Oncol 2008;111:13-7.

97. Vieira SC, Sousa RB, Tavares MBAC, et al. Preoperative pelvic lymphoscintigraphy is of limited usefulness for sentinel lymph node detection in cervical cancer. Eur J Obstet Gynecol Reprod Biol 2009;145:96-9.

98. Acharya BC, Jihong L. Sentinel lymph node detection in patients with early cervical cancer. JNMA J Nepal Med Assoc 2009;48:287-91.

99. Fotiou S, Zarganis P, Vorgias G, et al. Clinical value of preoperative lymphoscintigraphy in patients with early cervical cancer considered for intraoperative lymphatic mapping. Anticancer Res 2010;30:183-8.

100. Ogawa S, Kobayashi H, Amada S, et al. Sentinel node detection with $(99 \mathrm{~m}) \mathrm{Tc}$ phytate alone is satisfactory for cervical cancer patients undergoing radical hysterectomy and pelvic lymphadenectomy. Int J Clin Oncol 2010;15:52-8.

101. Kato H, Todo Y, Minobe SI, et al. Previous conization on patient eligibility of sentinel lymph node detection for early invasive cervical cancer. Int J Gynecol Cancer 2011;21:1491-4.

102. Roy M, Bouchard-Fortier G, Popa I, et al. Value of sentinel node mapping in cancer of the cervix. Gynecol Oncol 2011;122:269-74.

103.Lécuru F, Mathevet P, Querleu D, et al. Bilateral negative sentinel nodes accurately predict absence of lymph node metastasis in early cervical cancer: results of the SENTICOL study. J Clin Oncol 2011;29:1686-91.

104. Díaz-Feijoo B, Pérez-Benavente MA, Cabrera-Diaz S, et al. Change in clinical management of sentinel lymph node location in early stage cervical cancer: the role of SPECT/ CT. Gynecol Oncol 2011;120:353-7.

105. Devaja O, Mehra G, Coutts M, et al. A prospective singlecenter study of sentinel lymph node detection in cervical carcinoma: is there a place in clinical practice? Int J Gynecol Cancer 2012;22:1044-9.

106.Zhang Z, Chang Q. Clinical analysis of sentinel lymph node identification in patients with cervical cancer. Eur J Gynaecol Oncol 2014;35:26-31.

107.Kim JH, Kim DY, Suh DS, et al. The efficacy of sentinel 
lymph node mapping with indocyanine green in cervical cancer. World J Surg Oncol 2018;16:52.

108. Marnitz S, Köhler C, Bongardt S, et al. Topographic distribution of sentinel lymph nodes in patients with cervical cancer. Gynecol Oncol 2006;103:35-44.

109. Bader AA, Winter R, Haas J, et al. Where to look for the sentinel lymph node in cervical cancer. Am J Obstet Gynecol 2007;197:678.e1-7.

110. Frumovitz M, Ramirez PT, Levenback C. Lymphatic mapping and sentinel node detection in gynecologic malignancies of the lower genital tract. Curr Oncol Rep 2005;7:435-43.

111.Ansink AC, Sie-Go DM, van der Velden J, et al. Identification of sentinel lymph nodes in vulvar carcinoma patients with the aid of a patent blue $\mathrm{V}$ injection: a multicenter study. Cancer 1999;86:652-6.

112. Ansari M, Rad MAG, Hassanzadeh M, et al. Sentinel node biopsy in endometrial cancer: systematic review and meta-analysis of the literature. Eur J Gynaecol Oncol 2013;34:387-401.

113. Barlin JN, Khoury-Collado F, Kim CH, et al. The importance of applying a sentinel lymph node mapping algorithm in endometrial cancer staging: beyond removal of blue nodes. Gynecol Oncol 2012;125:531-5.

114.Persson J, Geppert B, Lönnerfors C, et al. Description of a reproducible anatomically based surgical algorithm for detection of pelvic sentinel lymph nodes in endometrial cancer. Gynecol Oncol 2017;147:120-5.

115. Tucker K, Staley SA, Gehrig PA, et al. Defining the learning curve for successful staging with sentinel lymph node biopsy for endometrial cancer among surgeons at an academic institution. Int J Gynecol Cancer 2020;30:346-51.

Cite this article as: Dabi Y, Bendifallah S, Kolanska K, Boudy AS, Querleu D, Akladios C, Zilberman S, Darai E, Touboul C. Anatomical basis of lymph node detection in gynecologic cancers: a review from a surgical perspective. Chin Clin Oncol 2021;10(2):15. doi: 10.21037/cco-20-228
116. Benoit L, Balaya V, Guani B, et al. Nomogram Predicting the Likelihood of Parametrial Involvement in EarlyStage Cervical Cancer: Avoiding Unjustified Radical Hysterectomies. J Clin Med 2020;9:2121.

117. Balaya V, Bresset A, Guani B, et al. Pre-operative surgical algorithm: sentinel lymph node biopsy as predictor of parametrial involvement in early-stage cervical cancer. Int J Gynecol Cancer 2020;30:1317-25.

118. Dabi Y, Willecocq C, Ballester M, et al. Identification of a low risk population for parametrial invasion in patients with early-stage cervical cancer. J Transl Med 2018;16:163.

119. Tranoulis A, Laios A, Theophilou G, et al. The Impact of Saphenous Vein Sparing During Inguinal Lymphadenectomy on Postoperative Morbidity in Women With Vulval Cancer: An Updated Per-Groin Metaanalysis of Short-term Outcomes. Int J Gynecol Cancer 2018;28:1232-8.

120. Oonk MH, van Hemel BM, Hollema H, et al. Size of sentinel-node metastasis and chances of non-sentinelnode involvement and survival in early stage vulvar cancer: results from GROINSS-V, a multicentre observational study. Lancet Oncol 2010;11:646-52.

121.Kumar A, Wallace SA, Cliby WA, et al. Impact of Sentinel Node Approach in Gynecologic Cancer on Training Needs. J Minim Invasive Gynecol 2019;26:727-32.

122. Dell'Orto F, Laven P, Delle Marchette M, et al. Feasibility of sentinel lymph node mapping of the ovary: a systematic review. Int J Gynecol Cancer 2019;29:1209-15.

123. Kleppe M, Kraima AC, Kruitwagen RFPM, et al. Understanding Lymphatic Drainage Pathways of the Ovaries to Predict Sites for Sentinel Nodes in Ovarian Cancer. Int J Gynecol Cancer 2015;25:1405-14. 